\title{
Dynamics of Tomato spotted wilt virus Replication in the Alimentary Canal of Two Thrips Species
}

\author{
F. M. de Assis Filho, R. A. Naidu, C. M. Deom, and J. L. Sherwood
}

Department of Plant Pathology, The University of Georgia, Athens 30602.

Accepted for publication 29 March 2002.

\section{ABSTRACT}

Assis Filho, F. M. de, Naidu, R. A., Deom, C. M., and Sherwood, J. L. 2002. Dynamics of Tomato spotted wilt virus replication in the alimentary canal of two thrips species. Phytopathology 92:729-733.

Transmission of Tomato spotted wilt virus (TSWV) is dependent on virus uptake in the midgut prior to virus movement to the salivary glands. Replication of TSWV in the alimentary canal of tobacco thrips (TT, Frankliniella fusca) and western flower thrips (WFT, F. occidentalis) was investigated by immunolocalization of the nonstructural protein (NSs) encoded by the small RNA of TSWV and fluorescence microscopy. Analysis of cohorts during development from larva to adults following virus acquisition by first instar larva indicated that virus replication fol- lowed a specific time-course pattern in the foregut, regions of the midgut, salivary glands, and ligaments between the midgut and salivary glands. Initial virus replication occurred only in epithelial cells of midgut- 1 but, upon infection of muscle cells, the virus moved to the midgut-2, foregut, midgut- 3 , and salivary glands. The ligaments between the midgut and salivary glands appeared to be a route for virus to invade the salivary glands. No virus replication was observed in the hindgut, Malpighian tubules, or tubular salivary glands. The dynamics of TSWV replication, as measured by NSs accumulation, were similar in both TT and WFT.

Additional keywords: immunolabel, thrips-transmission.
Tomato spotted wilt virus (TSWV) is the type species of the genus Tospovirus in the family Bunyaviridae (30). The virus is transmitted by several thrips species in a propagative manner (13, 23,32 ). Only immature thrips that acquire TSWV, or adults deriving from such immature thrips, transmit the virus $(18,20,24,28)$. The mechanism governing TSWV uptake by the thrips vector is not well understood. Several studies indicate a receptor-mediated process involving the TSWV glycoproteins $(\mathrm{G} 1 / \mathrm{G} 2)$ as the viral attachment molecules and a cellular receptor or receptors in the thrips midgut are required to promote virus entry $(4,9,11)$. In Frankliniella occidentalis (western flower thrips [WFT]), lack of transmission by second instar larva and adults has been related to the lack of virus uptake, despite virus ingestion $(24,28)$. However, Nagata et al. (15) showed that, despite virus uptake by WFT, there was limited accumulation of a defective RNA-containing isolate in the midgut of larva, and virus transmission was impeded. Similarly, in Thrips setosus, the lack of virus transmission was related to the restriction of virus to the midgut of larva, preventing virus movement to the salivary glands (17).

Whereas there is uncertainty about the initial acquisition of TSWV by thrips, virus must reach the salivary glands to be transmitted to the plant host during the feeding process (21), and transmission may not occur when there is limited virus accumulation in the salivary glands (16). Most information on the dynamics of TSWV in the thrips vector leading to transmission involves WFT. Investigation of other thrips species is important to identify similarities and differences in intrinsic factors that may mediate the TSWV-thrips interaction leading to virus transmission among species (13) or populations of the same species (29).

The thrips' alimentary canal consists of three morphologically distinct regions: the foregut (anterior region), the midgut and the hindgut (posterior region) (12). The midgut is divided into three

Corresponding author: J. L. Sherwood; E-mail address: sherwood@uga.edu

Publication no. P-2002-0523-01R

(C) 2002 The American Phytopathological Society regions: $\mathrm{mg} 1$ (anterior), mg2 (central), and mg3 (posterior) $(7,27)$. The midgut is composed of a single layer of epithelial cells separated from the midgut lumen by the peritrophic matrix. On the haemolymph side there is a lattice work of inner circular and outer longitudinal muscles (12). Studies on WFT suggested that the thrips midgut epithelial cells are the initial sites of entry for TSWV during acquisition and that the virus subsequently infects muscle cells surrounding the midgut and eventually the salivary glands $(16,25,26)$. Invasion of salivary glands has been proposed to occur through the ligaments that connect the salivary glands to mg1 (16).

In this study, two TSWV vector species were used to compare the dynamics of virus replication in a time-course manner to better understand the TSWV-thrips interaction that leads to virus transmission. A preliminary report has been published (1).

\section{MATERIALS AND METHODS}

Virus isolate, plant material, and thrips colony. A previously described TSWV isolate (19) that is transmissible by F. fusca (tobacco thrips [TT]) and WFT was maintained on Emilia sonchifolia by WFT transmission. TT and WFT colonies were reared and maintained in the laboratory on green bean pods as previously described (24). Initial identification of thrips and periodic confirmations were done using morphological characters of adults (14).

Virus acquisition. First instar larva of both TT and WFT, up to $24 \mathrm{~h}$ old, were given a 16-h acquisition access period (AAP) by feeding on excised leaves of TSWV-infected E. sonchifolia. After the AAP, the insects were transferred to green bean pods and reared to adults. Samples for immunolabeling were collected at the end of the AAP ( 0 h postacquisition [hpa]), then $24,48,72,96$, 120 , and $168 \mathrm{hpa}$ (corresponding to first and second larval stages); at the prepupal and pupal stages (typically 5 to 11 days postacquisition [dpa]), and at the adult stage (typically 2-, 9-, 16- and 23-day-old insects, corresponding to 14, 21, 28, and 35 dpa, respectively). Prepupal, pupal, and adult stages were recognized as described by van Rijn et al. (31). Virus-free control insects were 
similarly processed except virus-free leaves were used as the feeding source. For each time point, 32 insects (TT or WFT), includeing 8 TSWV-free insects, were dissected. The experiment was replicated two and three times for TT and WFT, respectively. A total of 2,080 thrips of both species were initially processed, but 585 thrips were lost during fixation. Thus, 1,495 thrips were observed for this study after the immunolabeling procedure.

Immunolabeling of alimentary canal and salivary glands. The whole-mount immunofluorescent staining technique (16) was used with the following modifications. Live thrips were immobilized by placing in a drop of acetone on a glass slide coated with poly-L-lysine (Sigma-Aldrich, St Louis). The alimentary canal was dissected using a dissecting scope (Wild M5-52173, Heerburgg, Switzerland) by cutting between the first and second thorax segments with a surgical blade (\#11, Feather Safety Razor Co. Ltd., Japan) and then kept in deionized water until fixation. Dissected alimentary canals were fixed with cold acetone for $20 \mathrm{~min}$ at $4{ }^{\circ} \mathrm{C}$ and allowed to air dry at room temperature (RT) for a 3 to $5 \mathrm{~min}$. All the following steps were done at RT. Nonspecific binding sites were blocked with 5\% nonfat dried milk (NFDM) for $30 \mathrm{~min}$, and then the alimentary canals were incubated for $2 \mathrm{~h}$ with monoclonal anti-nonstructural protein (anti-NSs) antibodies (3) at $2 \mu \mathrm{g} / \mu \mathrm{l}$ diluted in phosphate buffered saline (PBS), $\mathrm{pH} 7.4$, $+1 \%$ NFDM. After washing three times for 5 min with PBS, the alimentary canals were incubated for $1 \mathrm{~h}$ with the conjugate antibody (Alexa Fluor 488 goat anti-mouse immunoglobulin G conjugate; Molecular Probes, Eugene, OR) at $0.02 \mu \mathrm{g} / \mu \mathrm{l}$ diluted in PBS, $\mathrm{pH} 7.4,+1 \%$ NFDM. Incubation with conjugate antibody and all subsequent steps were conducted protected from direct light. After two washings with PBS for 5 min each, the alimentary canals were mounted following manufacturer's instructions (Slow Fade Light Antifade Kit, Molecular Probes) and examined using a fluorescent microscope (Model Labophot; Nikon Corp., Tokyo, Japan, equipped with a photometrics digital camera [Roper Scientific, Tucson, AZ) using a B-2A filter. The following controls were used: alimentary canal from virus-free thrips; no primary antibody; no secondary antibody; and a monoclonal primary antibody specific against an unrelated virus (Peanut stripe mosaic virus [PStV]).

\section{RESULTS}

A total of 1,495 insects, fed for $16 \mathrm{~h}$ on either healthy or TSWV-infected leaves at the larval stage, were used for immunolabeling. The dynamics of TSWV replication were similar in both species studied (Table 1). The first sign of specific labeling was observed at the end the AAP ( $0 \mathrm{hpa})$ and was characterized by an extensive bright green pattern in epithelial cells of mg1 (Fig. 1A).

TABLE 1. Immunolocalization of Tomato spotted wilt virus in the alimentary canal (AC) of Frankliniella fusca (tobacco thrips [TT]) and F. occidentalis (western flower thrips [WFT])

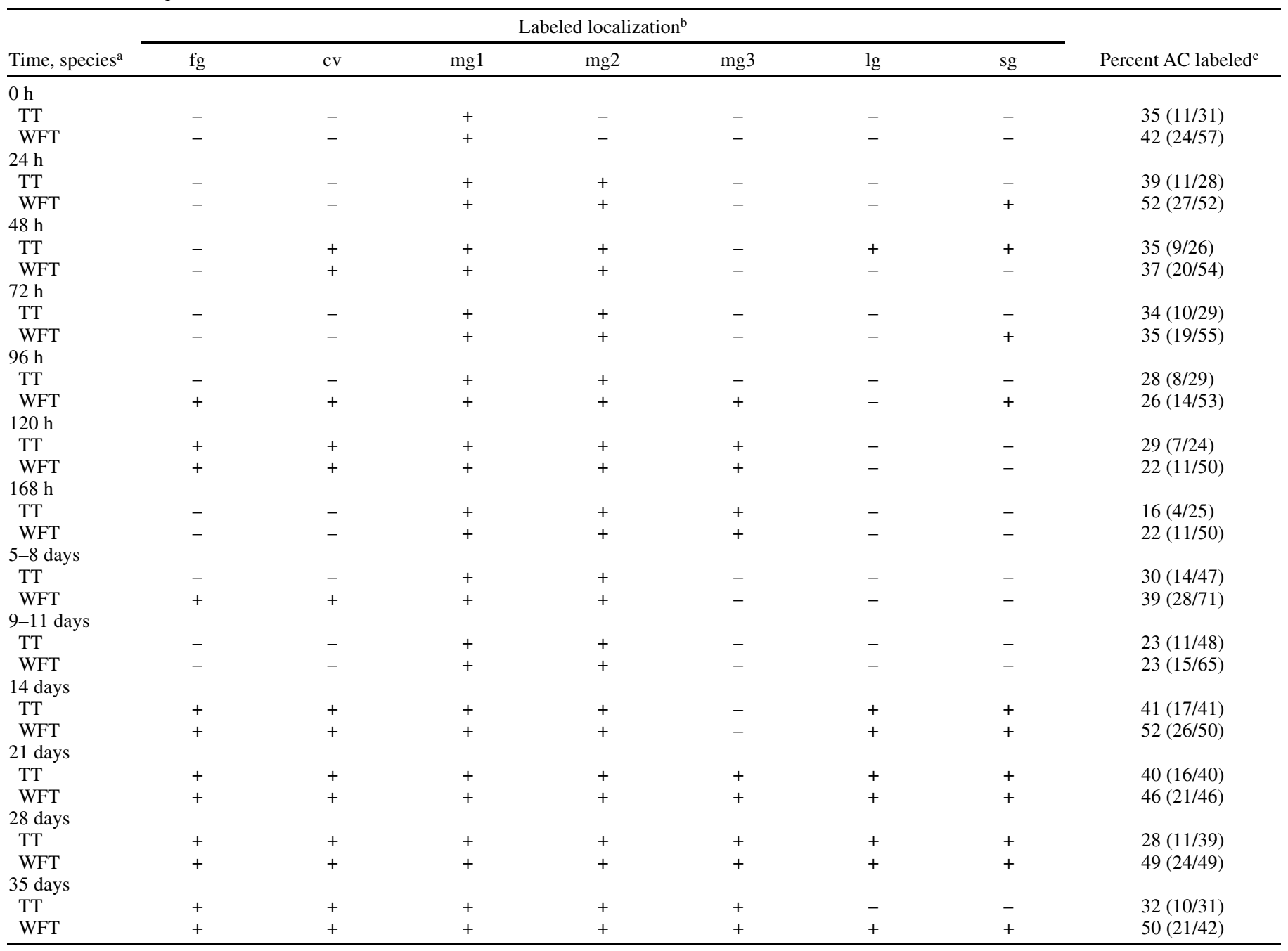

${ }^{a}$ Hours or days postacquisition.

${ }^{\mathrm{b}} \mathrm{fg}=$ foregut, $\mathrm{cv}=$ cardiac valve, $\mathrm{mg} 1=$ midgut $-1, \mathrm{mg} 2=$ midgut $-2, \mathrm{mg} 3=$ midgut $-3, \mathrm{~g}=$ ligaments, $\mathrm{sg}=$ salivary glands, $-=$ absence of immunolabel, $+=$ presence of immunolabel.

${ }^{c}$ Numbers in parentheses $=$ number of AC labeled/number of AC examined. 


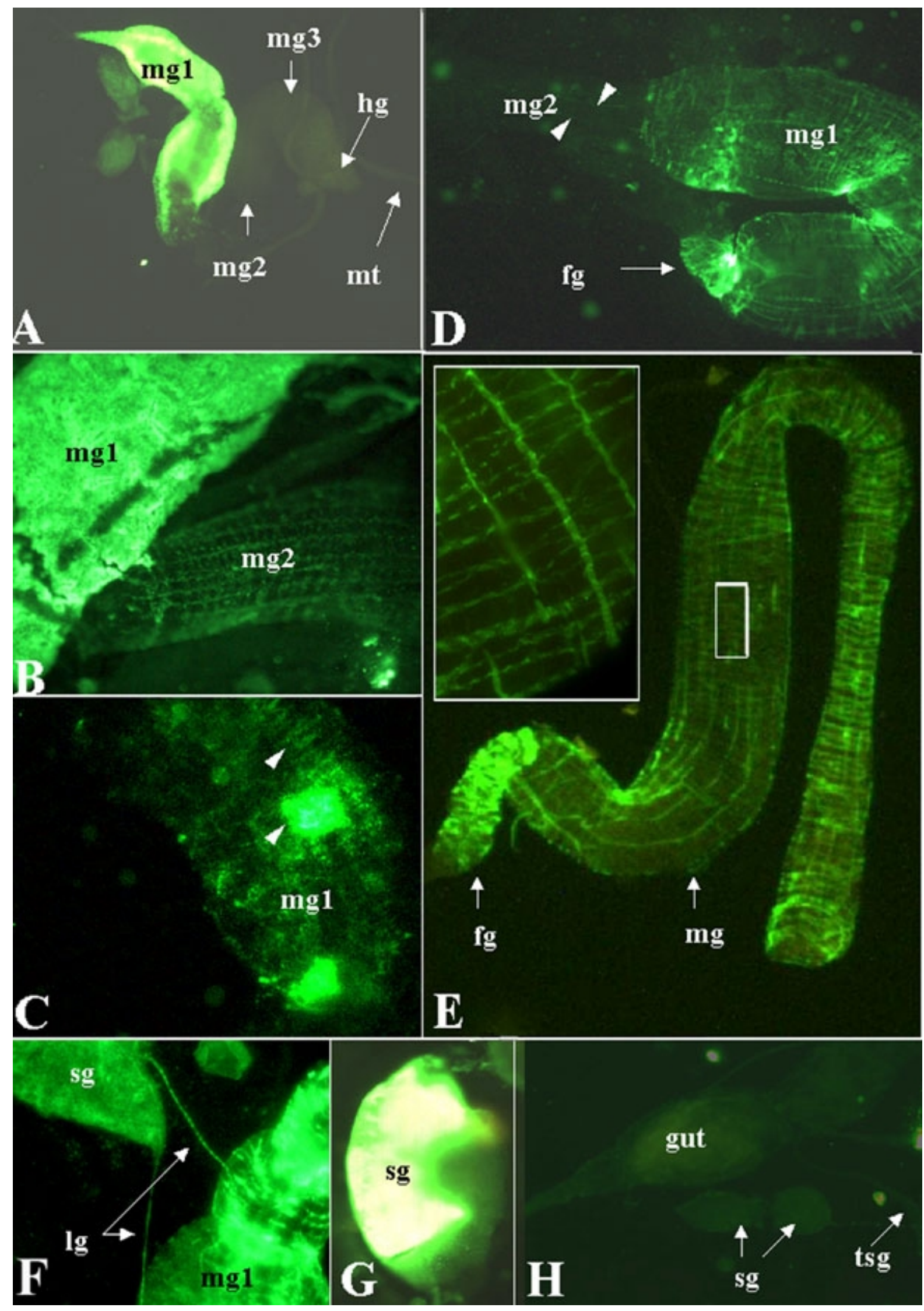

Fig. 1. Tomato spotted wilt virus (TSWV) infection of the alimentary canal of two thrips vectors demonstrated by immunofluorescence microscope. A, Alimentary canal from larva of western flower thrips (WFT) $0 \mathrm{~h}$ postacquisition (hpa) showing label at midgut-1 (mg1) only. B, Alimentary canal from larva of tobacco thrips (TT) 24 hpa showing the bright green label in midgut-1 (mg1) and the lattice pattern label in midgut-2 (mg2). C, Midgut from pupa of TT showing spotted label (arrow head). D, Alimentary canal from young adult of WFT showing label at mg1, foregut (fg), and anterior mg2 (arrow head). E, Alimentary canal from old adult of WFT showing label in the entire midgut $(\mathrm{mg})$ and foregut (fg). Insert; higher magnification of midgut region showing the lattice pattern label (muscle cells) and complete absence of epithelial label (bright green). F, Label of salivary gland (sg), ligaments (lg), and anterior mg1 of WFT. G, Label of salivary gland (sg) of WFT. H, Negative control, alimentary canal from TSWV-free adult of WFT; gut = alimentary canal; tsg = tubular salivary gland. 
In addition to the bright green pattern, a nascent lattice pattern characteristic of labeled muscle cells was observed in mg1 (data not shown). At $24 \mathrm{hpa}$, label was detected in muscle fibers surrounding $\mathrm{mg} 1$ and $\mathrm{mg} 2$ (lattice pattern), whereas the extensive bright green remained restricted to $\mathrm{mg} 1$ (Fig. 1B). Label also was observed in the salivary glands. The label was observed $48 \mathrm{hpa}$ at the cardiac valve (junction between foregut and midgut) and at the ligaments. Label at the foregut and mg3 was observed by $96 \mathrm{hpa}$ (Table 1). The label was not readily observed in the alimentary canals at the pupal stage, and was seen as either bright spots or a lattice pattern only in a small number of samples (Fig. 1C). In young adults ( 1 to 2 days old), only the lattice pattern (no bright green) was present in $\mathrm{mg} 1$, the posterior portion of the foregut, and a few muscle fibers anterior to mg2 (Fig. 1D). In older adults (over 1 week old), the lattice pattern was observed in the whole midgut and foregut (Fig. 1E). No labeling was observed in epithelial cells of adults. Whereas the foregut and midgut were frequently labeled, labeling of salivary glands and ligaments was observed only in $\approx 5 \%$ of larva and adults. To determine if immunolabeling at the epithelium was hidden by the stronger signal from muscle cells, a laser scanning confocal microscope was used to survey alimentary canals from both larva and adults. No indication of the epithelium being labeled was observed (data not shown).

Label was not observed in the hindgut (Fig. 1A), Malpighian tubules (Fig. 1A), and tubular salivary glands (Fig. 1H). Specificity of the label was confirmed by the absence of label in the alimentary canals of thrips fed on control plants subjected to the immunolabel procedure (Fig. $1 \mathrm{H}$ ). Similarly, the alimentary canals of thrips fed on TSWV-infected plants were not observed to be specifically labeled when the following controls were assayed (data not shown): omission of the primary antibody, omission of the secondary antibody, and replacement of the primary antibody by an unrelated monoclonal (anti-PStV).

\section{DISCUSSION}

The proposed models for uptake and movement of TSWV within thrips $(16,22)$ are based on virus accumulation. In this study, monoclonal antibody to NSs protein was used to identify virus replication within the thrips alimentary canal $(6,10,25)$, with emphasis on elucidating the process leading to virus spread along the alimentary canal. This study was done as a time-course from first instar larva to adult stages. The data obtained expands on previous findings with WFT by providing direct evidence of virus replication in the foregut, midgut, salivary glands, and ligaments; these are all sites identified for virus accumulation $(16,22)$. In addition, the dynamics of TSWV in TT was determined.

Our results indicate that, when TSWV was acquired by thrips larva, the virus initially replicated only in the epithelium of $\mathrm{mg} 1$. Initial virus replication in $\mathrm{mg} 1$ was followed by virus replication in muscle fibers surrounding the midgut immediately following a 16-h AAP. Ullman et al. (26) reported virus infection of muscle cells of larva as early as $48 \mathrm{~h}$ after acquisition feeding. At the second larval stage, virus replication was seen in epithelial cells of $\mathrm{mg} 1$, and in muscle cells of both the foregut and the three regions of the midgut. Previous reports indicated virus reached maximum accumulation before the prepupa stage $(22,33)$ or at the adult stage (28), suggesting extensive virus distribution sometime after initial replication at a restricted location. Initial virus replication appeared to be restricted to the epithelial cells of $\mathrm{mg} 1$ in immature stages, indicating (i) virus entry to the midgut does not occur at $\mathrm{mg} 2$ and $\mathrm{mg} 3$, (ii) there is no lateral movement into the epithelium of $\mathrm{mg} 2$, or (iii) only initially epithelial cells at $\mathrm{mg} 1$ support virus replication. Results from the present study indicate that virus entry occurs only at $\mathrm{mg} 1$, as has been observed by others $(17,22)$. It is interesting to note that Bandla et al. (2) detected the putative TSWV cellular receptor in $\mathrm{mg} 1, \mathrm{mg} 2$, and $\mathrm{mg} 3$ in WFT larva. When taken with observations that virus entry may be limited to mg1 (Fig. 1A and B), factors such as $\mathrm{pH}$ and ionic concentration may modulate virus acquisition.

In light of these findings, we propose that the initial site for TSWV entry and replication in TT and WFT is limited to the epithelial cells at mg1. The infection front then progresses to the muscle cells surrounding mgl of first instar larva. At the second instar larva, the infection front has moved backward and forward through the muscle fibers in the direction of $\mathrm{mg} 2$ and foregut, respectively. The bright green label restricted to the epithelium of mg1 of second instar larva is lost after pupation, which coincides with the possible absorption and renewing of this tissue during molting. In some insects, the midgut epithelium is continuously renewed; in others, the complete midgut epithelium is shed and immediately replaced; whereas, in others, insect cell replacement is rare or absent (5). Comprehensive information on the developmental changes in the thrips gut that occur during molting is lacking. We speculate that regenerative cells that differentiate into midgut epithelium, but not those that differentiate into muscle cells, may undergo apoptosis either due to virus infection or normal development, resulting in the virus-free condition of the newly formed epithelium. Cells from which muscle cells regenerate serve as a source of continued virus infection and hence give rise to the characteristic lattice pattern observed herein and by Nagata et al. (16). This model would explain the complete absence of TSWV in epithelium of adults. At the adult stage, TSWV moves laterally only through the muscle cells, and completely invades foregut and midgut muscle cells (Fig. 1D and E). Observation of the initial invasion of the posterior portion of the foregut and the anterior portion of $\mathrm{mg} 2$ (Fig. 1D) supports this proposition. The absence of movement from muscle to epithelial cells would result in the absence of TSWV in epithelium of $\mathrm{mg} 1$ of adults, and absence from $\mathrm{mg} 2$ and $\mathrm{mg} 3$ regardless of insect age.

A pair of salivary glands surrounds the foregut in WFT. The salivary glands are connected to the anterior portion of the midgut by a pair of ligaments, and to the posterior portion of the midgut by a pair of tubular salivary glands (27). From the observations made in this study, a similar anatomy is likely in TT. Access of TSWV to the salivary glands appears to occur via ligaments (Fig. $1 F)$. Tubular salivary glands never were found containing TSWV, whereas evidence of TSWV replication was observed in the ligaments in this study and by Nagata et al. (16). With arboviruses and their vectors, the source of infection of the salivary glands is the haemolymph (8), a route completely different from the one proposed here. There is only one report of TSWV in thrips hemocoel (24). The role of the ligaments in thrips development as well as virus movement needs further investigation.

No differences were observed in the dynamics of TSWV in TT and WFT under the conditions reported here. This report provides a better understanding of the thrips-TSWV relationship regarding TSWV dynamics and movement within the insect vector after virus uptake.

\section{ACKNOWLEDGMENTS}

This work was supported by funding from the Georgia Agricultural Experiment Station and USDA-CSREES Special Grant 99-34412-7415. We thank M. Brown, G. Freshour, and C. Mims for suggestions; T. Denny for assistance with the fluorescence microscope; and J. Shields for assistance with the laser scanning confocal microscope.

\section{LITERATURE CITED}

1. Assis Filho, F. M., Naidu, R., Deom, C. M., and Sherwood, J. L. 2001. The dynamics of Tomato spotted wilt virus (TSWV) replication in the alimentary canal tissues of a thrips vector. (Abstr.) Phytopathology 91(suppl.):S4.

2. Bandla, M. D., Campbell, L. R., Ullman, D. E., and Sherwood, J. L. 1998. Interaction of tomato spotted wilt tospovirus (TSWV) glycoproteins with a thrips midgut protein, a potential cellular receptor for TSWV. Phytopathology 88:98-104. 
3. Bandla, M. D., Westcot, D. M., Chenault, K. D., Ullman, D. E., German, T. L., and Sherwood, J. L. 1994. Use of monoclonal antibody to the nonstructural protein encoded by the small RNA of tomato spotted wilt tospovirus to identify viruliferous thrips. Phytopathology 84:14271431.

4. Bandla, M. D., Westcot, D. M., Ullman, D. E., and Sherwood, J. L. 1996. Thrips midgut proteins that bind to tomato spotted wild tospovirus glycoproteins. Acta Hortic. 431-342-349.

5. Billingsley, P. F., and Lehane, M. J. 1996. Structure and ultrastructure of the insect midgut. Pages 3-30 in: Biology of the Insect Midgut. M. J. Lehane and P. F. Billingsley, eds. Chapman \& Hill, London.

6. De Hann, P., Wagemakers, L., Peters, D., and Goldbach, R. 1990. The S RNA segment of tomato spotted wilt virus has an ambisense character. J. Gen. Virol. 71:1001-1007.

7. Del Bene, G., Dallai, R., and Machini, D. 1991. Ultrastructure of the midgut and the adhering tubular salivary glands of Frankliniella occidentalis (Pergande) (Thysanoptera:Thripidae). Int. J. Insect Morphol. Embryol. 20:15-24.

8. Hardy, J. L., Houk, E. J., Kramer, L. D., and Reeves, W. C. 1983. Intrinsic factors affecting vector competence of mosquitoes for arbovirus. Annu. Rev. Entomol. 28:229-262.

9. Kikkert, M., Meurs, C., van de Wetering, F., Dorfmuller, S., Peters, D., Kormelink, R., and Goldbach, R. 1998. Binding of tomato spotted wilt virus to a 94-kDa thrips protein. Phytopathology 88:63-69.

10. Kormelink, R., Kitajima, E. W., de Haan, P., Zuidema, D., Peters, D., and Goldbach, R. 1991. The nonstructural protein (NSs) encoded by the ambisense S RNA segment of tomato spotted wilt virus is associated with fibrous structures in infected plant cells. Virology 181:459-468.

11. Medeiros, R. B., Ullman, D. E., Sherwood, J. L., and German, T. L. 2000. Immunoprecipitation of a $50-\mathrm{kDa}$ protein: A candidate receptor component for tomato spotted wilt tospovirus (Bunyaviridae) in its main vector, Frankliniella occidentalis. Virus Res. 67:109-118.

12. Moritz, G. 1997. Structure, growth and development. Pages 15-63 in: Thrips as Crop Pest. T. Lewis, ed. CABI, Wallingford, UK.

13. Mound, L. A. 1996. The thysanoptera vector species of tospoviruses. Acta Hortic. 431:298-309.

14. Mound, L. A., and Kibby, G. 1998. Thysanoptera-An Identification Guide. 2nd ed. CABI, Wallingford, UK

15. Nagata, T., Inoue-Nagata, A. K., Prins, M., Goldbach, R., and Peters, D. 2000. Impeded thrips transmission of defective Tomato spotted wilt virus isolates. Phytopathology 90:454-459.

16. Nagata, T., Inoue-Nagata, A. K., Smid, H. M., Goldbach, R., and Peters, D. 1999. Tissue tropism related to vector competence of Frankliniella occidentalis for tomato spotted wilt tospovirus. J. Gen. Virol. 80:507515.

17. Ohnishi, J., Hosokawa, D., Fujisawa, I., and Tsuda, S. 1998. Tomato spotted wilt tospovirus movement into salivary glands during pupation at the thrips vector, Thrips setosus, is associated with the transmissibility. Pages 51-53 in: Recent Progress in Tospovirus and Thrips Research. D. Peters and R. Goldbach, eds. Agricultural University, Wageningen, the Netherlands.

18. Paliwal, Y. C. 1974. Some properties and thrip transmission of tomato spotted wilt virus in Canada. Can. J. Bot. 52:1177-1182.

19. Pappu, H. R., Todd, J. W., Culbreath, A. K., Bandla, M. D., and
Sherwood, J. L. 1998. First report on the multiplication of tomato spotted wilt tospovirus in tobacco thrips Frankliniella fusca. Plant Dis. $82: 1282$.

20. Sakimura, K. 1963. Frankliniella fusca, an additional vector for the tomato spotted wilt virus, with notes on Thrips tabaci, a thrips vector. Phytopathology 53:412-415.

21. Sherwood, J. L., German, T. L., Whitfield, A. E., Moyer, J., and Ullman, D. E. 2001. Tospoviruses. Pages 1034-1040 in: Encyclopedia of Plant Pathology. O. C. Maloy and T. D. Murray, eds. John Wiley \& Son, New York.

22. Tsuda, S., Fujisawa, I., Ohnishi, J., Hosokawa, D., and Tomaru, K. 1996. Localization of tomato spotted wilt tospovirus in larvae and pupae of the insect vector Thrips setosus. Phytopathology 86:1199-1203.

23. Ullman, D. E. 1996. Thrips and tospoviruses: Advances and future directions. Acta Hortic. 431:310-324.

24. Ullman, D. E., Cho, J. J., Mau, R. F. L., Westcot, D. M., and Custer, D. M. 1992. A midgut barrier to tomato spotted wilt virus acquisition by adults western flower thrips. Phytopathology 82:1333-1342.

25. Ullman, D. E., German, T. L., Sherwood, J. L., Westcot, D. M., and Cantone, F. A. 1993. Tospovirus replication in insect vector cells: Immunocytochemical evidence that the nonstructural protein encoded by $\mathrm{S}$ RNA of tomato spotted wilt tospovirus is present in thrips vector cells. Phytopathology 83:456-463.

26. Ullman, D. E., Westcot, D. M., Chenault, K. D., Sherwood, J. L. German, T. L., Bandla, M. D., Cantone, F. A., and Duer, H. L. 1995. Compartmentalization, intracellular transport, and autophagy of tomato spotted wilt tospovirus proteins in infected thrips cells. Phytopathology 85:644-654.

27. Ullman, D. E., Westcot, D. M., Hunter, W. B., and Mau, R. F. L. 1989. Internal anatomy and morphology of Frankliniella occidentalis (Pergande) (Thysanoptera:Thripidae) with special reference to interactions between thrips and tomato spotted wilt virus. Int. J. Insect Morph. Embryol. 18:289-310.

28. Van de Wetering, F., Goldbach, R., and Peters, D. 1996. Tomato spotted wilt tospovirus ingestion by first instar larvae of Frankliniella occidentalis is a prerequisite for transmission. Phytopathology 86:900-905.

29. Van de Wetering, F., van der Hoek, M., Goldbach, R., Mollema, C., and Peters, D. 1999. Variation in tospovirus transmission between populations of Frankliniella occidentalis (Thysanoptera:Thripidae). Bull. Entomol. Res. 89:579-588.

30. Van Regenmortel, M. H. V., Fauquet, C. M., Bishop, D. H. L., Carstens, E. B., Estes, M. K., Lemon, S. M., Moniloff, J., Mayo, M. A., McGeoch, D. J., Pringle, C. R., and Wickner, R. B. 2000. Virus taxonomy. Pages 599-621 in: Seventh Report of the ICTV. Academic Press, New York.

31. Van Rijn, P. C. J., Chris, M., and Steenhuis-Broers, G. M. 1995. Comparative life history studies of Frankliniella occidentalis and Thrips tabaci (Thysanoptera:Thripidae) on cucumber. Bull. Entomol. Res. 85: 285-297.

32. Webb, S. E., Kok-Yokomi, M. L., and Tsai, J. H. 1997. Evaluation of Frankliniella occidentalis as a potential vector of tomato spotted wilt virus. (Abstr.) Phytopathology 87:S102.

33. Wijkamp, I., van Lent, J., Kormelink, R., Goldbach, R., and Peters, D. 1993. Multiplication of tomato spotted wilt virus in its insect vector, Frankliniella occidentalis. J. Gen. Virol. 74:341-349. 